\title{
ИНФОРМАЦИОННАЯ ИНТЕГРАЦИЯ В ЕВРАЗИЙСКОМ ЭКОНОМИЧЕСКОМ СОЮЗЕ: ПРЕИМУЩЕСТВА И МЕТОДИКА ОЦЕНКИ РАЗВИТИЯ
}

\begin{abstract}
К.В. Якушенко*
Представлены преимущества информационной интеграции государств-членов в рамках развития интеграционного объединения. Определено состояние информационного пространства ЕАЭС по основным направлениям сотрудничества. Для оценки эффективности влияния информационной интеграции на развитие интеграционного объединения предложена методика, основанная на использовании количественных интегральных показателей.
\end{abstract}

Ключевые слова: информационная интеграция, интегральные индексы, ЕАЭС.

JEL-классификация: F15, F40.

DOI: $10.46782 / 1818-4510-2020-3-106-117$

Материал поступил 26.03.2020 乙.

Единое информационное пространство (ЕИП) является структурным продолжением единого экономического пространства и необходимым компонентом современных взаимодействий на межрегиональном уровне. Основными факторами, выгодно отличающими ЕИП от иных форматов взаимодействия, являются его многомерность и единство формата представленных данных, а также синергетическое расширение информационного охвата при сочетании разнородных акторов из различных информационных сообществ. Процесс интеграционного взаимодействия в экономическом смысле сближает и объединяет государства на основе согласования национальных политик в разных областях. Несомненно, это создает условия для свободного перемещения и информационных потоков. Информационная интеграция закономерно становится необходимым условием и потенциалом для построения ЕИП интеграционного объединения с целью обеспечения скорости, полноты и точности получения сведений и данных в современных условиях хозяйствования. Новые реалии глобализирующегося мира заставляют поиному взглянуть на процессы информационной интеграции, в том числе и для евразийского пространства (в частности, для
ЕАЭС как яркого представителя евразийства). В государствах - членах ЕАЭС накоплен определенный массив данных по созданию информационных пространств на национальном уровне, который при определенной теоретической переработке может дать ответы на вопросы в области межрегиональных информационных коммуникаций (Коуз, 1993; Глазьев, 2002; Shibusawa, 2000; Бияков, 2004; Дзялошинский, 2001; Кочетов, 2001; Делягин, 2003; Зуев, 2014; Лопатин, 2000; Никитенко, 2006) ${ }^{1}$. Однако остается малоизученным вопрос формирования ЕИП на наднациональном уровне. Необходимо определить состояние информационной интеграции на евразийском пространстве, оценить влияние информационной интеграции на развитие EАЭС.

\section{Преимущества информащионной интеграции}

Информационная интеграция представляет собой процесс объединения потоков информационных сигналов, циркулирующих

${ }^{1}$ Гуревич С.М. 2004. Экономика отечественных СМИ: учебное пособие. Москва: Аспект пресс. 287 с.; Макаров В.Л., Васильев В.А. 1984. Информаиионное равновесие и ядро в обобщенных моделях обмена. Доклад Академии наук СССР. Т. 275. № 3. С. 549-553.

\footnotetext{
* Якушенко Ксения Валентиновна (Yakush.K.V@mail.ru), кандидат экономических наук, доцент, Белорусский национальный технический университет (г. Минск, Беларусь).
} 
на различных уровнях взаимодействия, и коммуникационного обеспечения, осуществляемом на основе технологий унифицированных сообщений и представления данных, в рамках интеграционного объединения. В данном процессе превращение информации в непосредственную производительную силу становится основой новой информационной или сетевой экономики, которая функционирует в пределах ЕИП (Дятлов, 2001). ЕИП становится основной платформой для деятельности любого общественного института, способствует взаимопроникновению, быстрому обмену и свободному распространению информации и знаний для граждан.

На данном этапе развития общества информационное взаимодействие стало одним из важнейших факторов трансформации общества. В информационном обществе возрастает ценность информации и знаний, увеличивается роль информационно-коммуникационных технологий в ВВП и необходимость создания единого информационного пространства, обладающего внутренней идентичностью, общими целями, задачами и доступностью для всех участников этого пространства с целью получения, обмена и использования информации в различном виде.

Российский экономист А.И. Орлов (2007) отмечает в качестве важнейших черт развития информационной экономики будущего свободу передачи информации и равноправное участие всех субъектов информационных отношений в выработке и реализации решений. ЕИП позволит сбалансировать направления современной экономической сферы, в которой именно информация играет сегодня одну из основных ролей. Следовательно, необходимо переходить к новой экономической системе или реструктуризации старой на информационной основе. Как отмечалось ранее, важный момент перехода от рыночной экономики к информационному обществу заключается в том, что капитал как основа его существования уже не является главным фактором производства. Его место занимают знания и информация, которые стимулируют развитие новых наукоемких технологий, отражающихся, в свою очередь, на производстве. Серьезную критику также вызывает созданное в условиях ры- ночной экономики общество потребления, которое часто ведет к деградации личности и разбалансированию экономических институтов.

Фактически общество потребления не вписывается в современные условия, требующие повышения роли государства в экономике, обеспечивая тем самым социальную защищенность граждан (Krugman, 2008. P. 26). Адекватная экономическая политика вполне совместима с экономическим ростом. Положительно расценивая процесс глобализации и свободной торговли, П. Кругман выступает за активную экономическую позицию государства для обеспечения справедливого распределения доходов. Причины роста неравенства лежат в политике, а не в экономике.

Свободный рынок может значительно увеличить доходы, но не может «правильно» их распределять, чтобы сделать общество справедливым. А потому рыночная экономика не может быть предоставлена самой себе. Это предопределяет иной путь развития. Только информатизация общества может обеспечить динамичное управление экономикой и скоординировать действия государства и частных предпринимателей.

Следует отметить, что японский вариант концепции информационного общества разработан в конце 60-х - начале $70-x$ годов XX в., и прежде всего для решения задач экономического развития Японии. В начале 1960-х годов была создана Общегосударственная автоматизированная система управления экономикой страны (ОГАС) (Глушков, 1975. С. 89). На создание этой системы, по его расчетам, требовалось минимум 15-20 лет. «Когда появится государственная автоматизированная система управления, мы будем легко охватывать единым взглядом всю экономику. На новом историческом этапе, с новой техникой, на новом возросшем уровне мы как бы «проплываем» над той точкой диалектической спирали, ниже которой, отделенный от нас тысячелетиями, остался лежать период, когда свое натуральное хозяйство человек без труда обозревал невооруженным глазом» (Там же).

По мнению Г.С. Теслера (2000), формула К. Маркса «Деньги - Товар - Деньги» в постиндустриальном информационном обще- 
стве будет выглядеть следующим образом: ДЕНЬГИ + ИНФОРМАЦИЯ - ЗНАНИЯ И ИДЕИ - ТЕХНОЛОГИЯ - ОРГАНИЗАЦИЯ ПРОИЗВОДСТВА - ТОВАР - НОВЫЕ ЗНАНИЯ + ИНФОРМАЦИЯ ОРГАНИЗАЦИЯ СБЫТА - СБЫТ ДЕНЬГИ + ЗНАНИЯ + ИНФОРМАЦИЯ.

Таким образом, акцент ставится на процессы распределения, обмена и потребления материальных благ на основе постоянно обновляемой информации. Меняется и роль предпринимателя, он должен превратиться в аналитика и организатора производства и сбыта товара. «Для постиндустриального информационного общества, наряду с обычными категориями, такими как деньги, товар, производительность, предприниматель и производство, начинают играть первостепенную роль такие понятия, как получение, хранение, структурирование, переработка и передача знаний, технологические революции, аналитика производства и т. д.» (Там же).

Формирование ЕИП призвано обеспечить стабилизацию вышеуказанных процессов посредством новейших информационных технологий, что позволит:

- обеспечить динамическое управление экономикой на основе обновляемых баз данных, аналитики и прогнозов развития экономических моделей;

- способствовать накоплению знаний и, как следствие, повысить эффективность организации технологии производства, а также сбыта продукции;

- создать предпосылки новой технологической революции и внедрения ее результатов на производстве;

- обеспечить финансовую стабильность при разумной системе энерго- и ресурсосбережения.

На современном этапе развития общество уже достигло достаточно высокого технологического уровня, способного обеспечить свободный доступ к информации на международном уровне. Территориальность государственных границ в информационном пространстве видоизменяется, облегчая обмен информацией и ее использование. Это обеспечит создание условий для успешной координации действий государства и частного бизнеса и станет платформой для их кооперации.
Во-первых, ЕИП позволит повысить информированность всех участников процесса. Это важно как для компаний различного масштаба, так и для рядовых потребителей. Сокращение издержек на поиск необходимых товаров и услуг, анализ рынка спроса и предложения приведут к оптимизации многих экономических процессов.

Во-вторых, снизятся время и затраты на поиск информации. Эффект снижения информационного шума подразумевает, что будут созданы условия и критерии для более качественного отбора необходимой информации. Этим сегодня не обладает современный Интернет, выдавая в поисковике все, что в той или иной степени может касаться задаваемого вопроса.

В-третьих, создание ЕИП приведет к сокращению трансакционных издержек (на взаимодействие) на всех уровнях. С точки зрения современной институциональной теории, экономическим основанием существования экономических организаций является наличие трансакционных издержек (Шадрин, 2001). Формирование ЕИП стремительно сократит данные издержки и, как следствие, трансформирует существующие политические и экономические институты. Снижение издержек в коммуникации позволит говорить о новом этапе в развитии международных экономических связей.

Отметим основные преимущества координации в ЕИП:

- уменьшение затрат на поиск поставщика, поскольку сравнение цен, товаров и услуг будет менее дорогостоящим. Это особенно важно в случае низкой плотности субъектов ЕИП в определенном географическом регионе;

- информационное пространство обеспечивает потребителей лучшей информацией о характеристиках товара, при этом покупная цена будет включать и оплату информации о необходимом товаре или услуге;

- для производителя преимущество заключается в использовании гарантированных поставок в случае отсутствия товара в режиме онлайн и, как следствие, увеличении контроля за большим количеством потенциальных покупателей. Нет необходимости в создании значительного коли- 
чества пунктов розничной или оптовой торговли и др.

B-четвертых, идет формирование сетевых управленческих структур на различных уровнях, происходит трансформация межличностных отношений. В частности, это касается установления информационного партнерства, происходит группировка пользователей по информационным интересам и т. д.

Необходимо также учитывать, что современная международная торговля во многом состоит из глобальных цепочек добавленной стоимости (ГЦДС), в рамках которых услуги, сырье, компоненты и части товара движутся между странами, прежде чем быть интегрированными в финальной продукт, который, в свою очередь, поставляется потребителям во всем мире. ГЦДС являются ключевым элементом мировой экономики, позволяющим странам интеграционного объединения специализироваться на наиболее эффективных видах деятельности и повышать свой инновационно-промышленный потенциал без необходимости создания собственных отраслей там, где возможно приобретение недостающих товаров и услуг за рубежом². Эволюция цепочек добавленной стоимости тесно связана с процессами региональной интеграции, которая, с одной стороны, усиливает участие сторон интеграционных проектов в ГЦДС - в силу снижения пошлин и уменьшения барьеров для торговли и других взаимодействий. С другой стороны, высокий уровень участия стран в таких цепочках увеличивает шансы на заключение интеграционных соглашений ${ }^{3}$. Создание ЕИП в интеграционном объединении позволит обсуждать процессы участия стран в ЦДС и более эффективно взаимодействовать государствам-членам в направлении формирования ГЦДС посредством:

${ }^{2}$ Рекомендации ОЭСР по участию в глобальных цепочках создания добавленной стоимости. Обеспечение представленности данных по странам ЕАЭС в базе данных TiVA.2017. Сотрудничество государств-членов ЕАЭС с ОЭСР в контексте развития интеграционной повестки Союза. Возможности использования наилучших практик ОЭСР в работе ЕАЭС. C. 29-32. URL: https://clck.ru/MKCKM

${ }^{3}$ Asia-Pacific trade and investmentreport 2015: Supporting Participation in Value Chains. URL: https:// www.unescap.org/sites/default/files/publications/APTIR\% 202015_Full\%20Report.pdf создания баз данных о возможных партнерах, передовых разработках и инновационных подходах в странах интеграционного объединения;

информирования о лучших практиках других интеграционных объединений по участию в ГЦДС и информационного обеспечения по поддержке в процессах их имплементации.

Конечной целью должна быть реализация интеграционного потенциала объединения, улучшение позиций государств-участниц в рамках ГЦДС, а следовательно, и уровня экономического благосостояния в целом.

Специфика интеграционных группировок заключается в принятии соглашений наднациональными (или надрегиональными) объединениями на экономическом или политическом уровне на добровольной основе. Формирование ЕИП возведет интеграцию на совершенно новый уровень, обеспечивая эффективное экономическое взаимодействие, поскольку будет предоставлять равные условия для всех участников и нивелирует препятствующие обмену информацией границы.

Таким образом, в общем плане функции ЕИП интеграционных группировок заключаются в следующем:

- способствовать распространению информации между всеми субъектами информационных отношений;

- содействовать сохранению и обновлению информации;

- структурировать информационные ресурсы с учетом выработки единых критериев;

- обеспечивать свободный, безопасный и безбарьерный доступ к информации.

Общая линейка субъектов ЕИП разворачивается от крупнейших компаний и корпораций до частных рядовых потребителей товаров и услуг, в число которых будут входить и микропредприятия. Прежде всего следует отметить, что ЕИП предоставляет каждому из них равные возможности в поиске информации.

Для крупных субъектов сфера интересов может разворачиваться в области взаимодействия с такими же предприятиями и компаниями (B2B) или с рядовыми потребителями (B2C). Отдельная сфера - это 
подбор персонала, поиск работы по найму и другие области рынка труда. Взаимодействие корпораций и частных лиц осуществляется посредством их интересов или работы по найму. Для рядовых потребителей, как представителей домохозяйств, это, например, поиск и покупка товаров и услуг, работы и т. д. Следует отметить, что потребитель сам может стать производителем на микроуровне или просто продавать те или иные товары. Например, домохозяйства могут продавать вышедшие из употребления вещи. Самозанятые и предприниматели будут взаимодействовать не только с компаниями, но и с частными лицами. Регулирующими и управляющими этой структурой должны стать исполнительный, законодательный и судебный органы власти, учитывающие специфику информационных отношений.

Эффективное функционирование ЕИП не только обеспечит развитие экономических отношений, подняв их на новый уровень интеграционных группировок, но и привлечет представителей из других сфер - социальной, политической и т. д., усиливая интеграционные процессы. При этом роль ЕИП заключается в формировании таких условий, которые были бы выгодны для всех субъектов информационных отношений - как для стран, интегрированных компаний, так и частных лиц. Этот процесс приведет к общему снижению издержек на производстве не только для участников ЕИП группировки, но и для тех, кто находится за его пределами, отвечая законам ценообразования и конкуренции.

\section{Состояние информащионного пространства ЕАЭС}

Формирование ЕАЭС стало результатом поиска формата и направлений взаимовыгодного сотрудничества. В условиях современной экономической реальности, характеризующейся тенденциями глобализации и регионализации, государства - члены ЕАЭС пошли по пути объединения (синергии) потенциалов национальных экономик в интересах их устойчивого развития. В настоящее время совокупные экономические возможности государств - членов ЕАЭС создают широкие интеграционные возможности для усиления влияния на развитие мировой экономики.

Для обеспечения информационной интеграции ЕАЭС была сформирована интегрированная информационная система с целью создания единых баз данных и информационных ресурсов. Согласно документу «О регулировании отношений сторон в сфере информационно-коммуникационных отношений и информационного взаимодействия Договора о Евразийском экономическом союзе» ${ }^{4}$, были приняты направления работы по развитию данной системы (таможенное регулирование, техническое регулирование, макроэкономическая политика, промышленная политика и т. д.). Система призвана решать вопросы обмена информацией между государствами-членами в рамках формирования ЕИП на основе электронной формы взаимодействия. Здесь цифровая трансформация экономики выступает основополагающим (технологическим) базисом информационной интеграции.

Приведем краткую характеристику основных направлений информационного сотрудничества в рамках ЕАЭС.

Таможенное регулирование и внешнеэкономическая деятельность (ВЭД). Новый Таможенный кодекс ЕАЭС усилил процессы электронного межведомственного взаимодействия таможенных служб, дал участникам ВЭД возможность осуществлять операции посредством Интернета и тем самым снижать расходы на ведение своей деятельности. В частности, усовершенствовался механизм «единого окна», который позволяет согласовать обмен информацией и получить ряд выгод: увеличение экспорта товаров стран ЕАЭС; повышение конкурентоспособности на внешних рынках; прозрачность прохождения экспортно-импортных операций; уменьшение торговых барьеров внутри ЕАЭС и др.

Одновременно с этим выявляется ряд проблем в данной области:

недостаточная техническая оснащенность участников ВЭД;

высокая стоимость программного обеспечения в таможенном документообороте;

${ }^{4}$ URL: http://www.pravo.by/document/?guid=3871\&p0= F01400176 
отсутствие единообразия в подаче электронных документов.

Техническое регулирование. В сфере технического регулирования требуется установление соответствующих обязательных требований в ЕАЭС (технических регламентов). В данном вопросе большое значение имеет принятие комплекта технологических документов, которые регламентируют передачу информации между уполномоченными органами ЕАЭС: единство информационной формы свидетельства о государственной регистрации продукции, создание системы информирования о провозе опасной продукции, единая нормативная база регистрации лекарств, унификация сведений о государственной регистрации продукции и др.

Вместе с тем в ЕАЭС на данный момент отсутствует системная подача информации по вопросам технического регулирования, набирает обороты нелегальная выдача сертификатов соответствия.

Интеграчия и макроэкономическая политика. По данному направлению также важно формирование общего информационного взаимодействия. Здесь, в частности, играет роль создание информационной платформы Коллегии Евразийской экономической комиссии («Электронная Коллегия»). Данная платформа призвана в режиме цифрового реального времени принимать соответствующие решения по работе Комиссии и позволяет облегчить документооборот и голосование представителей государств - членов объединения.

Промышленность и агропромышленный комплекс. По данному направлению начали работать определенные проекты, связанные с информационной интеграцией в ЕАЭС:

введена в эксплуатацию витрина сервисов евразийской информационной системы промышленности для поиска партнеров внутри объединения;

разработана инфраструктура евразийских технологических платформ, на базе которых тестируются индустриально-информационные проекты (платформы «Биомедицина», «Светодиоды», «ЕвразияБИО» и др.);

введен в эксплуатацию информационный ресурс по сортам сельскохозяйственных растений и др.
Энергетика. Несмотря на то, что топливно-энергетический комплекс ЕАЭС играет большую роль для государств-членов (определены Концепция формирования общего рынка газа, нефти и нефтепродуктов; Концепция формирования общего электроэнергетического рынка), корректной работы по правилам информационного обмена в данном направлении не проводится. Также отсутствует единая система информационного оповещения в случае атомной аварии (хотя в СНГ такая система существовала).

транспорт и инфраструктура. В части развития информационной интеграции транспорта можно отметить, что данное направление в большой степени регулируется на национальном уровне: применяются совершенно разные национальные программы развития отрасли, отсутствует общая стратегия совершенствования инфраструктуры, присутствует недостаточная унификация документов. Все это приводит к слабому информационному взаимодействию в ЕАЭС.

Финансовая сфера. Достижениями в данном направлении могут являться следующие проекты Соглашений: о порядке обмена сведениями, входящими в состав кредитных историй, в рамках Евразийского экономического союза; об обмене информацией в электронном виде между налоговыми органами государств - членов Евразийского экономического союза об уплаченных суммах косвенных налогов; об обмене информацией в сфере противодействия легализации (отмыванию) доходов, полученных преступным путем, и финансирования терроризма при перемещении наличных денежных средств и (или) денежных инструментов через таможенную границу $\mathrm{EA}^{5} \mathrm{C}^{5}$ и др. Принятие большого количества документов в финансовой сфере говорит о ее достаточной разработанности, однако существуют определенные недоработки:

недостаточная разработка вопроса по обмену финансовой информацией при обеспечении информационной безопасности;

разница административных барьеров в финансовой сфере.

5 URL: http://www.eurasiancommission.org/ru/ Documents/Годовой отчет 2017.pdf 
Торговая политика. Одной из главных задач в данной сфере является создание информационной системы поддержки экспорта в рамках ЕАЭС, обеспечение условий для продвижения евразийских компаний в глобальные цепочки добавленной стоимости. В связи с этим отсутствует общая информационная стратегия ЕАЭС, имеется недостаточная информационная осведомленность хозяйствующих субъектов о возможностях партнеров соседних государств, отсутствует планомерная информационная работа по разъяснению бизнесу особенностей форматов торгово-экономических взаимодействий ЕАЭС с третьими странами.

\section{Влияние информащионной интегращии на развитие ЕАЭС}

Для оценки эффективности влияния информационной интеграции на развитие интеграционного объединения предложена методика, основанная на использовании количественных интегральных показателей. К таким показателям были отнесены следующие: индекс готовности страны к сетевому взаимодействию в едином информационном пространстве; индекс развития информационно-коммуникационных технологий (ИКТ) в интеграционном объединении; индекс развития экономики знаний государств-членов; индекс готовности к электронному правительству государствчленов; индекс Бертельсманна; индекс качества наднационального государственного управления.

Все индексы являются составными, включающими в себя различные показатели. Полученные значения дают представление о развитии информационного пространства страны. До настоящего момента измерения проводились международными организациями для каждого конкретного государства, при этом отсутствовала методика расчета применительно к интеграционному объединению. Для того, чтобы произвести оценку развития информационной интеграции в ЕАЭС на основе выделенных показателей, предложено рассчитать позицию объединения как средневзвешенное значение, пропорциональное вкладу государства-члена в суммарный ВВП ЕАЭС. Такой расчет показывает влия- ние экономического производства на развитие информационного пространства ЕАЭС (оценивает рыночную составляющую пространства всех государств-членов, входящих в ЕАЭС). Расчетный период - 2015-2018 гг. (по одним индексам данные предоставляются международными организациями ежегодно, по другим - 1 раз в три года). Одновременно с этим можно утверждать, что в ЕАЭС разноуровневая, разноскоростная интеграция (в связи с чем и развивается ускоренными темпами интеграционное взаимодействие Беларуси и России). Исходя из этого, целесообразно произвести расчет позиции в соответствующем рейтинге также по усеченной схеме, при которой средняя позиция ЕАЭС представляется только через государства, входящие в ядро интеграции (Россия, Беларусь, Казахстан).

По индексу развития ИКТ в ЕАЭС наилучшие позиции занимает Беларусь (32-е место в рейтинге), далее следуют Россия, Казахстан, Армения и Кыргызстан (рис. 1). ЕАЭС в общем рейтинге занимает 44-е (2015 г.) и 46-е место (2016 г.). При расчете рейтинга на 3 страны ЕАЭС улучшает свои позиции на 1 пункт.

Индекс готовности государств - членов ЕАЭС к сетевому взаимодействию в информационном пространстве (индекс сетевой готовности) был рассчитан только

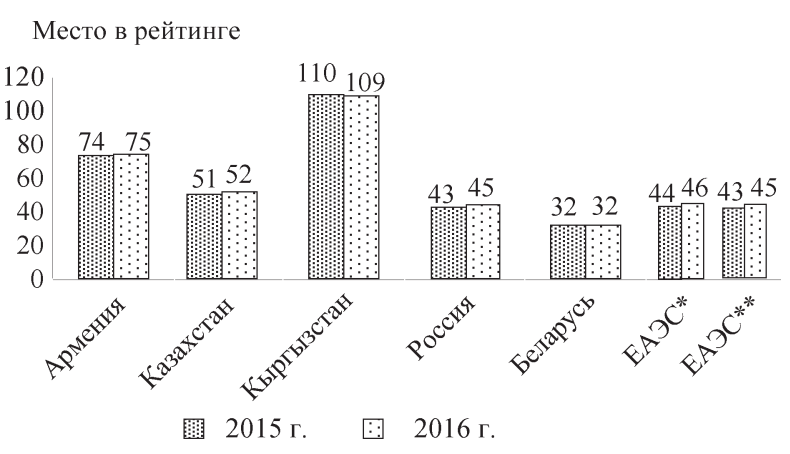

Рис. 1. Индекс развития ИКТ государств членов и всего ЕАЭС в целом

* ЕАЭС - средневзвешенное значение, пропорциональное вкладу государства-члена в суммарный ВВП ЕАЭС.

** Расчет рейтинга на 3 страны.

Источник. Авторская разработка на основе: ITUYearbookofStatistics 2017. Chronological Time Series 2007-2016. Geneva: International Telecommunication Union. URL: https://www.itu.int/en/ITU-D/Statistics/ Pages/publications/yb2017.aspx 
на 4 страны (Беларусь не предоставляет сведения для данного рейтинга) и на 2 страны (оставшееся ядро интеграции). В общем по рейтингу, при отсутствии Кыргызстана и Армении, существенных изменений не происходит (ЕАЭС остается на 41-й позиции в рейтинге). По показателям «Уровень использования ИКТ в общественном, коммерческом и государственном секторах» на 2016 г. и «Воздействие информационных технологий» (по показателям в 2015 г.) улучшение происходит на 1 позицию при расчете на 2 страны (рис. 2).

Индекс Бертельсманна (индекс управления) характеризует, насколько эффективно формируется и развивается институциональная среда интеграционного объединения. Он представлен такими показателями, как индекс состояния и индекс управления. Каждый из них описывает уровень политической и экономической трансформации страны, оценивает эффективность государственного менеджмента.

При расчете данного индекса (на полный состав ЕАЭС) наилучшие позиции занимают именно Кыргызстан и Армения, не входящие в ядро интеграции. Улучшения

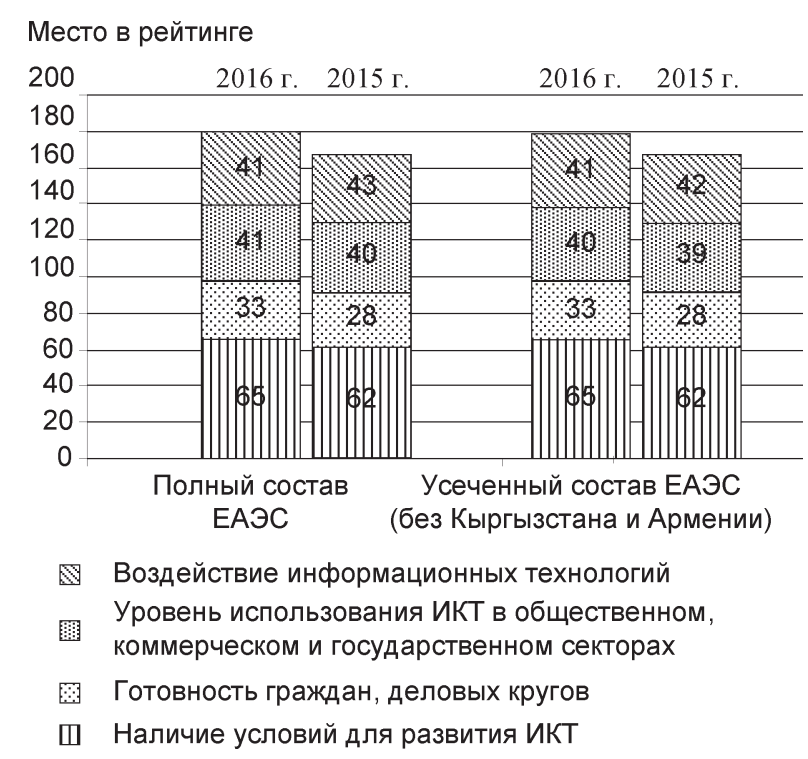

Рис. 2. Индекс сетевой готовности государств-членов по показателям, 2015-2016 гг.

Источник. Авторская разработка на основе: The Global Information Technology Report 2016. Innovating in the Digital Economy. URL: https://www.wsj.com/ public/resources/documents/GITR2016.pdf; The Global Information Technology Report 2015. Innovating in the Digital Economy. URL: https://www.wsj.com/public/ resources/documents/GITR2015.pdf позиций при отсутствии Кыргызстана и Армении не наблюдается. По показателю «Индекс управления» позиция снижается на 17 пунктов (рис. 3).

По рейтингу качества государственного управления в целом по ЕАЭС видна достаточно сильная разбежка в показателях: в 2016 г. по сравнению с 2015 г. улучшились позиции объединения по таким характеристикам, как «Контроль над коррупцией», «Качество регулирования», «Политическая стабильность и отсутствие преступности».

Если рассматривать изменения рейтинга в усеченном составе ЕАЭС, то улучшение позиций при отсутствии Кыргызстана и Армении не наблюдается, однако по показателям «Учет мнения населения и подотчетность государственных органов», «Эффективность государственного управления» (в 2015 г.) на 1 пункт снижается позиция ЕАЭС (рис. 4).

В двух последующих рейтингах при отсутствии Кыргызстана и Армении изменений позиций ЕАЭС не происходит. Так, в индексе развития экономики знаний (2018 г.) ЕАЭС занимает 17-ю позицию в мире (рис. 5), в индексе развития электронного правительства в 2018 г. по сравнению с 2016 г. - улучшает мировую позицию на 3 пункта (рис. 6).

Таким образом, по каждому рейтингу была просчитана позиция ЕАЭС с выделением места в рейтинге, который показал, что позиции ЕЭАС в мировом рейтинге ухудшаются (расчет на 3 страны) по показателям:

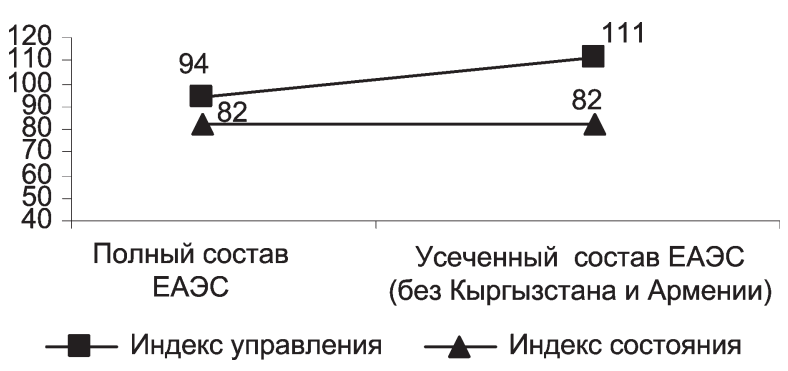

Рис. 3. Индекс Бертельсманна государств-членов по показателям, 2016 г.

Источник. Авторская разработка на основе: URL: https://www.bti-project.org/en/meta/downloads.html 


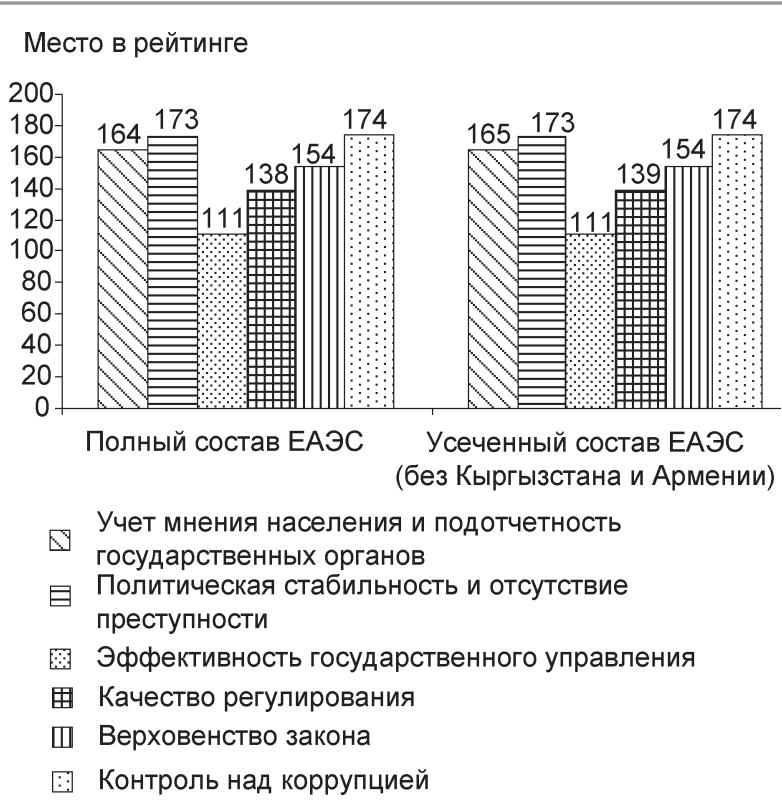

Рис. 4. Индекс качества государственного управления ЕАЭС по показателям, 2015 г.

Источник. Авторская разработка на основе: URL: http://info.worldbank.org/governance/wgi/Home/Reports

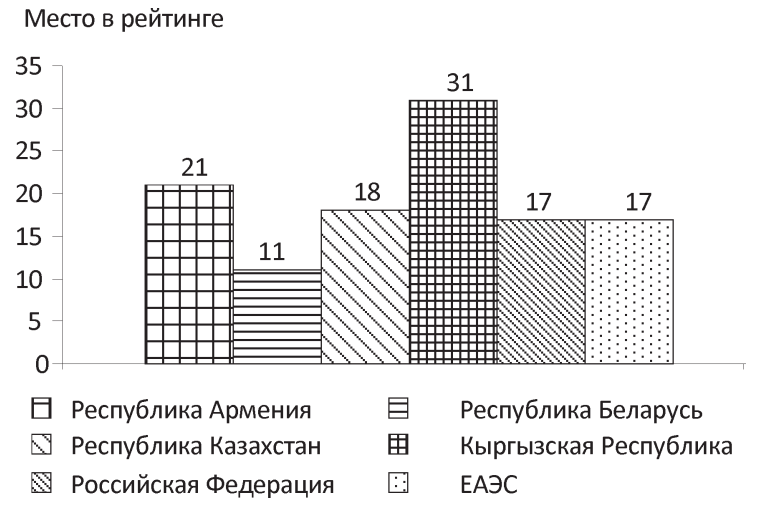

Рис. 5. Индекс развития экономики знаний в ЕАЭС, 2018 г.

Источник.Авторская разработка на основе: Introducing the EBRD Knowledge Economy Index.2019. London: European Bank for Reconstruction and Development.

индекс управления (в рейтинге Бертельсманна) - резко снижается позиция на 17 пунктов;

индекс качества государственного управления - по показателям «Учет мнения населения и подотчетность государственных органов», «Эффективность государственного управления» (2015 г.) снижается позиция на 1 пункт.

Подобный расчет без Кыргызстана и Армении, которые по социально-экономическим показателям отстают от России,

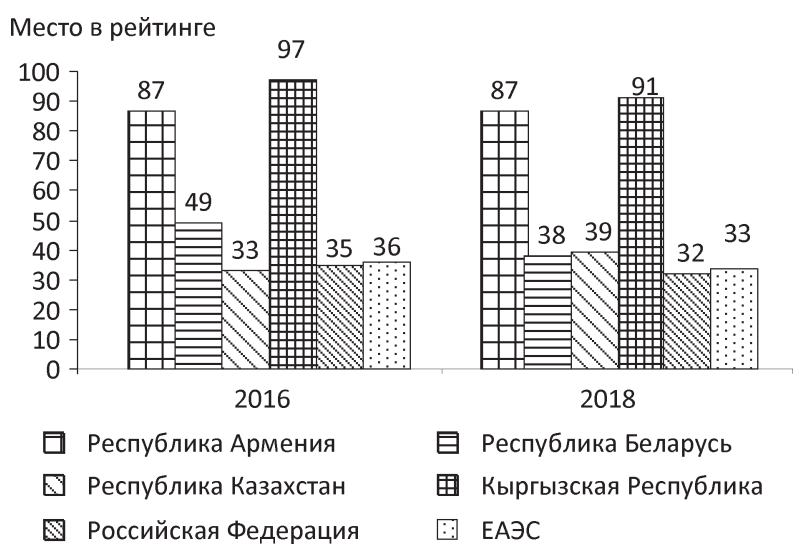

Рис. 6. Индекс развития электронного правительства в ЕАЭС, 2016-2018 гг.

Источник. Авторская разработка на основе: Исследование ООН: Электронное правительство 2018. Применение электронного правительства для формирования устойчивого и гибкого общества. Нью-Йорк: Организация объединенных наций. URL: publicadministration.un.org

Беларуси и Казахстана, косвенно доказывает, что у ядра интеграции выявляется существенная проблема: уклон в технологическую составляющую информационной интеграции и отсутствие сильной институциональной базы. Следовательно, оценивается только рыночная составляющая информационного пространства ЕАЭС. Однако нерыночная составляющая (институциональные связи, сетевые отношения, влияние человеческого капитала на развитие экономических процессов) не находит должного проявления. Происходит уклон только в технологическую основу со слабым развитием институциональной базы. Требуется дополнить методику не только расчетами показателей с учетом ВВП, но и расчетом показателей с учетом индекса на душу населения (НДН). В результате проведенного исследования выявлено, что улучшение позиций ЕАЭС в большей степени происходит по рейтингу качества государственного управления (рис. 7).

У стран, не входящих в ядро ЕАЭС (Армения и Кыргызстан), техническая база развивается слабее, однако идет усиленное развитие институциональной составляющей, нерыночной компоненты информационного пространства (в частности, по рейтингу качества государственного управления). Следовательно, в ЕАЭС при участии в интеграции пяти стран в любом случае развивается информационная интеграция 
с рыночной и нерыночной компонентами на базе технологического развития и усиливающейся институциональной основой.

Таким образом, формирование единого информационного пространства способно обеспечить условия для успешной координации действий государства, частного бизнеса и граждан интеграционного объединения и стать платформой для их кооперации. В результате:

повысится информированность всех участников экономического процесса (за счет сокращения издержек на поиск необходимых товаров и услуг, анализа рынка спроса и предложения и оптимизации экономических процессов);

снизятся время и затраты на поиск информации (за счет уменьшения эффекта «информационного шума»);

сократятся трансакционные издержки (на взаимодействие и координацию) на всех уровнях, и, как следствие, произойдет ускорение трансформации существующих политических и экономических институтов и стабилизация экономической системы интеграционного объединения в целом;

ускорятся процессы участия государств членов интеграционного объединения в цепочках добавленной стоимости (за счет создания баз данных о возможных партнерах, передовых разработках и инновационных подходах в странах интеграционного объединения; информирования о лучших практиках других интеграционных объединений по участию в цепочках добавленной стоимости и информационного обеспечения по поддержке в процессах их имплементации);

улучшится реализация интеграционного потенциала объединения, а следовательно, и уровень экономического благосостояния государств - участниц интеграционного объединения в целом (за счет обеспечения эффективного экономического взаимодействия внутри объединения при предоставлении равных условий для всех участников и нивелировании препятствующих обмену информацией границ).

Отметим, суть методики оценки эффективности влияния информационной интеграции на развитие регионального интеграционного объединения состоит в расчете индексов за счет ВВП и показателей ин-

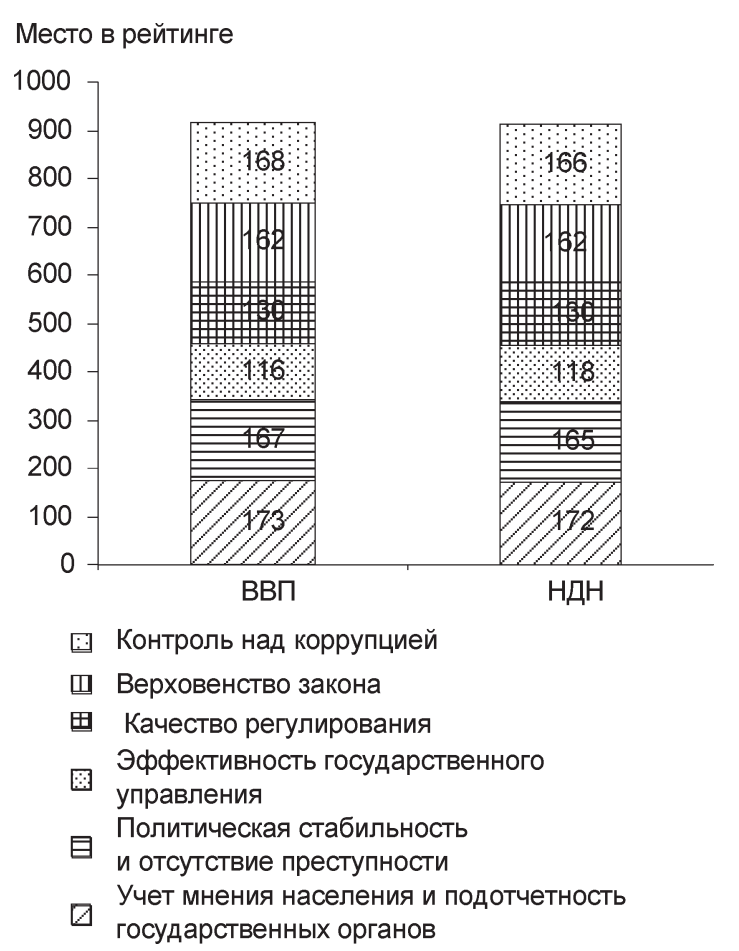

Рис. 7. Сравнение места ЕАЭС в рейтинге качества государственного управления с учетом ВВП и индекса на душу населения, 2018 г.

Источник. Авторская разработка на основе: $E \boldsymbol{\theta}$ разийский экономический союз в цифрах: краткий статистический сборник. 2018. Москва: Евразийская экономическая комиссия.

декса на душу населения; учете особенностей рыночной (развитие информационного рынка) и нерыночной (уровень развития институциональных связей, сетевых отношений) составляющих информационного пространства. Апробация методики на примере интеграционной организации ЕАЭС позволила оценить информационное взаимодействие в ЕАЭС, в том числе:

определить, что отличительной особенностью механизма является применение его на уровне международной экономической интеграции с учетом единства подходов к формированию и функционированию информационного пространства государств членов ЕАЭС;

осуществить расчет рейтинга на 5 и на 3 страны ЕАЭС на основе предложений автора по совершенствованию методики расчета рейтингов и с учетом особенностей разноуровневой и разноскоростной интеграции государств - членов ЕАЭС;

доказать важность учета нерыночной составляющей информационного пространства; 
определить особенности развития государств - членов ЕАЭС, входящих и не входящих в ядро интеграции, по индексам сетевой готовности, развития ИКТ, развития экономики знаний, готовности к электронному правительству и качеству государственного управления, индексу Бертельсманна (у ядра интеграции - Россия, Беларусь, Казахстан выявлен уклон в технологическую составляющую единого информационного пространства и отсутствие сильной институциональной базы; у Армении и Кыргызстана - идет усиленное развитие институциональной составляющей, нерыночной компоненты единого информационного пространства);

доказать, что в ЕАЭС при участии в интеграции 5-ти государств развивается единое информационное пространство с рыночной и нерыночной компонентой на базе технологического развития и усиливающейся институциональной основой;

использовать результаты оценки в качестве информационной и научной базы для разработки комплекса стратегических действий по совершенствованию информационного пространства государств - членов ЕАЭС.

\section{СПИСОК ЛИТЕРАТУРЫ (REFERENCES)}

Бияков О.А. 2004. Теория экономического пространства: методологический и региональный аспекты. Томск: Издательство Томского университета. 151 c. [Biyakov O.A. 2004. The theory of economic space: methodological and regional aspects. Tomsk: Izdatel'stvo Tomskogo universiteta. 151 p. (In Russ.)]

Глазьев С.Ю. 2002. Место России в меняющихся взаимоотношениях центра и периферии мировой экономики. Глобальная экономика: сущность, механизмы, перспективы: материалы международной научной конференции. Москва. URL: www.glazev.ru [Glaziev S.Yu. 2002. Russia's place in the changing relationship between the center and periphery of the world economy. Global'naya ekonomika: sushchnost', mekhanizmy, perspektioy: materialy mezhdunarodnoy nauchnoy konferentsii. Moscow. URL: www.glazev.ru (In Russ.)]

Глушков В.M. 1975. Макроэкономические модели и принщипь построения ОГАС. Москва: Статистика. [Glushkov V.M. 1975. Macroeconomic models and principles of construction of the OGAS. Moscow: Statistika. (In Russ.)]

Делягин М.г. 2003. Мировой кризис: общая теория глобализации. Москва: ИНФРА-М. 768 с.
[Delyagin M.G. 2003. World crisis: general theory of globalization. Moscow: INFRA-M. 768 p. (In Russ.)]

Дзялошинский И.М. 2001. Информационное пространство России: структура, особенности функционирования, перспективы эволющии. Москва: Московский центр Карнеги. 30 с. [Dzyaloshinskiy I.M. 2001. Information space of Russia: structure, features of functioning, prospects of evolution. Moscow: Moskovskiy tsentr Karnegi. 30 p. (In Russ.)]

Дятлов C.A. 2001. Макропропорции интернет-экономики. Развитие информащионного общества в России: сборник статей. Т. 1. Санкт-Петербург: Издательство Санкт-Петербургского университета. C. 165-171. [Dyatlov S.A. 2001. Macro proportions of the Internet economy. Razvitie informatsionnogo obshchestva v Rossii: sbornik statey. Vol. 1. Sankt-Peterburg: Izdatel'stvo SanktPeterburgskogo universiteta. PP. 165-171. (In Russ.)]

Зуев В.Н. 2014. Методология классификации и оценки форм региональной интеграции. Евразийская экономическая интеграчия. № 3. C. 25-43. [Zuev V.N. 2014. Methodology for classifying and evaluating forms of regional integration. Evraziyskaya ekonomicheskaya integratsiya. No 3. PP. 25-43. (In Russ.)]

Коуз Р.Г. 1993. Фирма, рынок и право. Москва: Дело. 192 с. [Kouz R.G. 1993. Firm, market and law. Moscow: Delo. 192 p. (In Russ.)]

Кочетов Э. 2001. Глобалистика как геоэкономика, как реальность, как мироздание: новый ренессанс - истоки и принципь его построения, фундаментальные опоры, теоретический и методологический каркас. Москва: Прогресс. 703 с. [Kochetov E. 2001. Globalistics as geo-Economics, as reality, as the universe: the new Renaissance-the origins and principles of its construction, the fundamental pillars, the theoretical and methodological framework. Moscow: Progress. 703 p. (In Russ.)]

Лопатин В.Н. 2000. Теоретико-правовые проблемы защиты единого информационного пространства и их отражение в системах российского права и законодательства. Труды по интеллектуальной собственности. № 1. C. 51-104. [Lopatin V.N. 2000. Theoretical and legal problems of protection of the unified information space and their reflection in the systems of Russian law and legislation. Trudy po intellektual'noy sobstvennosti. No 1. PP. 51-104. (In Russ.)]

Никитенко П.Г. 2006. Ноосферная экономика и сощиальная политика: стратегия инноващионного развития. Минск: Белорусская наука. 479 с. [Nikitenko P.G. 2006. Noosphere economy and social policy: the strategy of innovative development. Minsk: Belorusskaya nauka. 479 p. (In Russ.)]

Орлов А.И. 2007. Неформальная информационная экономика будущего. Неформальные ин- 
ституты в современной экономике России: сборник трудов конференции «Третьи Друкеровские чтения». Москва. С. 72-87. [Orlov A.I. .2007. The informal information economy of the future. Neformal'nye instituty v sovremennoy ekonomike Rossii: sbornik trudov konferentsii «Tret'i Drukerovskie chteniya». Moscow. PP. 72-87. (In Russ.)]

Теслер Г.С. 2000. Концепция построения постиндустриального информационного общества. Математичні машини і системи. № 2, 3. URL: http://www.immsp.kiev.ua/publications/2000_2_3/ files/tesler_2000_23.pd [Tesler G.S. 2000. The concept of building a post-industrial information society. Matematychni mashyny i systemy. No 2, 3. URL: http://www.immsp.kiev.ua/publications / 2000_2_3/files/tesler_2000_23.pd (In Russ.)]
Шадрин А.Е. 2001. Трансформация экономических и социально-политических институтов в условиях перехода к информационному обществу. Развитие информационного общества в России: сборник статей. Т. 1. Санкт-Петербург: Издательство Санкт-Петербургского университета. С. 173-183. [Shadryn A.E. 2001. Razvitie informatsionnogo obshchestva v Rossii: sbornik statey. Vol. 1. SanktPeterburg: Izdatel'stvo Sankt-Peterburgskogo universiteta. PP. 173-183. (In Russ.)]

Krugman P.R. 2008. The return of depression economics and the crisis of 2008. New York: W.W. Norton \& Company. 214 p.

Shibusawa H. 2000. Cyberspace and physical space in an urban economy. Papers in Regional Science. Vol. 79. Iss. 3. PP. 253-270.

In citation: Belorusskiy Economicheskiy zhurnal. 2020. No 3. PP. 106-117.

Belarusian Economic Journal. 2020. No 3. PP. 106-117.

\section{INFORMATION INTEGRATION IN THE EURASIAN ECONOMIC UNION: ADVANTAGES AND METHODOLOGY OF DEVELOPMENT ASSESSMENT}

\section{Kseniya Yakushenka ${ }^{1}$}

Authors affiliation: ${ }^{1}$ Belarusian National Technical University (Minsk, Belarus)

Corresponding author: Kseniya Yakushenka (Yakush.K.V@mail.ru).

ABSTRACT. The article introduces advantages of information integration among EAEU member states as part of integration associations in case of its further development. It also identifies the status of EAEU information space on the main lines of cooperation. A new methodology based on the use of quantitative integral indicators is suggested to assess the impact of information integration on integration associations and its effectiveness.

KEYWORDS: information integration, integral indexes, EAEU.

JEL-code: F15, F40.

DOI: $10.46782 / 1818-4510-2020-3-106-117$

Received 26.03.2020 